\title{
Investigating the impact of flow rate ramp-up on Carbon Dioxide start-up injection
}

\author{
Revelation J Samuel ${ }^{1}$ and Haroun Mahgerefteh \\ Department of Chemical Engineering, University College London, WC1E 7JE, UK \\ Received / Accepted / Published
}

\begin{abstract}
Carbon Capture and Storage (CCS) represents the technology for capturing carbon dioxide $\left(\mathrm{CO}_{2}\right)$ produced from large emission sources, such as fossil-fuel power plants, transporting and depositing it in underground geological formations, such as depleted oil and gas fields. $\mathrm{CO}_{2}$ injection flow rate ramp-up time is essential for the development of optimal injection strategies and bestpractice guidelines for the minimisation of the risks associated with the process. The rate of rapid quasi-adiabatic Joule-Thomson expansion when high pressure $\mathrm{CO}_{2}$ is injected into a low pressure injection well if not monitored carefully may lead to significant temperature drops posing several risks, including: blockage due to hydrate and ice formation with interstitial water. The paper employ a Homogeneous Equilibrium Mixture (HEM) model, where the mass, momentum, and energy conservation equations are considered for a mixture of liquid and gaseous phases assumed to be at thermal and mechanical equilibrium with one another. In particular, this study considers linearly ramped-up injection mass flow rate from 0 to $38.5 \mathrm{~kg} / \mathrm{s}$ over 5 minutes (fast), 30 minutes (medium) and 2 hours (slow). The reliability and applicability of the HEM model is tested against real-life $\mathrm{CO}_{2}$ injection experiment wellbore temperature data obtained from the Ketzin pilot site Brandenburg, Germany. The ramping up injection mass flow rate simulation results predicted the fast (5 mins) injection ramp-up as best option for the minimisation of the associated process risks.
\end{abstract}

Keywords: boundary conditions; carbon capture and storage; $\mathrm{CO}_{2}$ injection; ramp-up; transient model

\footnotetext{
${ }^{1}$ This work was supported in part by the Petroleum Technology Development Fund (PTDF) under Grant PTDF/E/OSS/PHD/SRJ/717/14 and the Department of Chemical Engineering, University College London. Corresponding author: Revelation Samuel specialises in multi-phase flow modelling, pipeline safety and risk management and CCS. Email: ucecrjs@ucl.ac.uk; Tel.: +44 2076793809
} 


\section{Introduction}

Carbon Capture and Storage (CCS) represents the technology for capturing carbon dioxide $\left(\mathrm{CO}_{2}\right)$ produced from large point sources, such as fossil-fuel power plants, transporting it, e.g. by pipelines, ships or trucks, and depositing it in underground geological formations, such as depleted oil and gas fields or saline aquifers. CCS is widely recognised as a key technology to meet the ambitious $2{ }^{\circ} \mathrm{C}$ agreement reached at the Paris COP 21 meeting (COP 21, 2015; UNFCCC, 2016). While CCS technology is promising, it is also very expensive, particularly due to the high costs of capture and compression, which have been the main focus of recent studies (Dennis Gammer, 2016). In addition, it has been pointed out that in order to reduce the costs of CCS, the integration between the various elements of its chain should be considered (IEAGHG, 2015). While this has been done mainly for $\mathrm{CO}_{2}$ capture/purification and transport processes, less attention has been paid to interfacing between the transportation and storage elements of CCS, which has become particularly important for the safe and optimal injection of $\mathrm{CO}_{2}$ into depleted gas fields (De Koeijer et al, 2014).

Depleted gas fields represent prime potential targets for the large-scale storage of captured $\mathrm{CO}_{2}$ emitted from industrial sources and fossilfuel power plants (Oldenburg et el, 2001). For instance, in the case of the UK, the Southern North Sea and the East Irish Sea depleted gas reservoirs provide 3.8 of the total 4-billiontonne storage capacity required to meet UK's $\mathrm{CO}_{2}$ reduction commitments for the period 2020-2050 (Hughes, 2009). Depleted gas reservoirs are often considered as preferential for $\mathrm{CO}_{2}$ storage, given their proven capacity to retain buoyant fluids and the availability of geological data, such as pressure, porosity and permeability, derived from years of gas production (Sanchez Fernandez et al., 2016). The UK has completed three large FEED study projects for offshore $\mathrm{CO}_{2}$ storage at Hewett, Goldeneye and Endurance sites (Cotton, Gray, \& Maas, 2017). In order to further the development of CCS and boost the confidence of both private investors and the public in the deployment of full-chain industrial CCS systems, it is of paramount importance to guarantee that the third element of the chain, i.e. the storage site, will be of high-quality and operate in safe conditions. A recent study has investigated the key factors having the highest impact on the safe storage of $\mathrm{CO}_{2}$ into depleted oil and gas fields (Hannis et al, 2017). In particular, key geological storage properties, such as pressure, temperature, depth and permeability, can affect injectivity and lead to variations in the $\mathrm{CO}_{2}$ flow. Therefore, changes in the operation of the storage sites will require flow and pressure management within the $\mathrm{CO}_{2}$ transportation network (Sanchez Fernandez et al., 2016).

The most effective way of transporting the captured $\mathrm{CO}_{2}$ for subsequent sequestration using high-pressure pipelines is in the dense phase (Böser \& Belfroid, 2013). The $\mathrm{CO}_{2}$ arriving at the injection well will typically be at pressure greater than 70 bar and at temperature between 4 and $8{ }^{\circ} \mathrm{C}$. Given the substantially lower pressure at the wellhead, the uncontrolled injection of $\mathrm{CO}_{2}$ will result in its rapid, quasi-adiabatic Joule-Thomson expansion leading to significant temperature drops (Curtis M. Oldenburg, 2007). This process could pose several risks, including:

- blockage due to hydrate and ice formation following contact of the cold sub-zero $\mathrm{CO}_{2}$ with the interstitial water around the wellbore and the formation water in the perforations at the near well zone;

- possible freezing of annular fluids (see Fig. 2) resulting in potential wellbore damage.

- thermal stress shocking of the wellbore casing steel as it cools beyond its specified lowest temperature leading to its fracture and escape of $\mathrm{CO}_{2}$;

- $\mathrm{CO}_{2}$ backflow into the injection system due to the violent evapouration of the expanding liquid $\mathrm{CO}_{2}$ upon entry into the low pressure wellbore. 
In order to minimise all these risks, accurate mathematical models are necessary to simulate the time-dependent behaviour of the $\mathrm{CO}_{2}$ injected into the well and subsequently released into the depleted reservoir, and thereby develop appropriate injection strategies to reduce the subsequent risks.

A significant amount of research has already been devoted to the analysis of the injection of $\mathrm{CO}_{2}$ from wells into underground reservoirs (André et al, 2007; Goodarzi et al, 2010; Nordbotten et al, 2005). However, as noted in Linga \& Lund, (2016) and Munkejord et al, (2016), the analysis of the transient behaviour of the $\mathrm{CO}_{2}$ flowing inside the injection wells has received limited attention in the literature, and more experimental data are needed (De Koeijer et al., 2014). Lu \& Connell, (2008) discussed a steady-state model to evaluate the flow of $\mathrm{CO}_{2}$ and its mixtures in non-isothermal wells. Paterson et al, 2008) simulated the temperature and pressure profile considering $\mathrm{CO}_{2}$ liquid-gas phase change in static wells, assuming a quasi-steady state and neglecting changes in kinetic energy. Lindeberg, (2011) proposed a model combining Bernoulli's equation for the pressure drop along the well and a simple heat transfer mechanism between the fluid and the surrounding rock. The model was applied to the Sleipner $\mathrm{CO}_{2}$ injection well. Pan et al, (2011) presented analytical solutions for steady-state, compressible two-phase flow through a wellbore under isothermal conditions using a drift flux model. Lu \& Connell, (2014) investigated a non-isothermal and unsteady wellbore flow model for multispecies mixtures. Ruan et al., (2013) and (Jiang et al., 2014) developed a two-dimensional radial numerical model to study $\mathrm{CO}_{2}$ temperature increase mechanisms in the tubing, and the impact of $\mathrm{CO}_{2}$ injection on the rock temperature in both axial and radial directions. Xiaolu $\mathrm{Li}, \mathrm{Xu}, \mathrm{Wei}$, \& Jiang, (2015) developed a model to account for the dynamics of $\mathrm{CO}_{2}$ into injection wells subject to highly-transient operations, such as start-up and shut-in. Linga \& Lund, (2016) discussed a two-fluid model for vertical flow applied to $\mathrm{CO}_{2}$ injection wells, predicting flow regimes along the well and computing friction and heat transfer accordingly. Xiaojiang Li et al., (2017) presented a unified model for wellbore flow and heat transfer in pure $\mathrm{CO}_{2}$ injection for geological sequestration, EOR and fracturing operations. Also recently, Samuel \& Mahgerefteh, (2017) published a paper on transient flow modelling of the start-up injection process without ramp-up. The study shows the consequent effect of quasi-adiabatic Joule-Thomson expansion when high pressure $\mathrm{CO}_{2}$ is injected into a low pressure injection well. Acevedo \& Chopra, (2017) conducted a prior work on transients and start up injection for the Goldeneye injection well. They studied the influence of phase behaviour in the well design of $\mathrm{CO}_{2}$ injectors. The study shows that during transient operations (closing-in and restarting injection operations), a temperature drop is observed at the top of the well for a short period of time. This is due to the reduction of friction caused by a lower injection rate. The duration of these operations dictates the extent to which the various well elements are affected. The sequence of steady state injection, closing-in operation (30 minutes), closed-in time (10minutes), and starting-up operation (30minutes) was simulated for the low reservoir pressure case using OLGA. However, no publication critically considered the flowrate ramping up times studied in this paper.

In this study, we investigate the $\mathrm{CO}_{2}$ injection flow rate ramp-up times which is driven by the need for the development of optimal injection strategies and best-practice guidelines for the minimisation of the risks associated with the process. Investigating injection flow rate ramp-up is essential in understanding the rate of rapid, quasi-adiabatic Joule-Thomson expansion when high pressure $\mathrm{CO}_{2}$ is injected into a low pressure injection well. A Homogeneous Equilibrium Model (HEM), where the mass, momentum, and energy conservation equations are considered for a mixture of liquid and gaseous phases assumed to be at thermal and mechanical equilibrium with one another is employed. Fluid/wall friction, gravitational force, and heat 
transfer between the fluid and the outer well layers are also taken into account.

\section{Development of mathematical model}

Fig. 1 shows a schematic flow diagram of a typical injection well. A control volume consisting of a section of the tube is considered for the analysis and derivation of model governing equations.

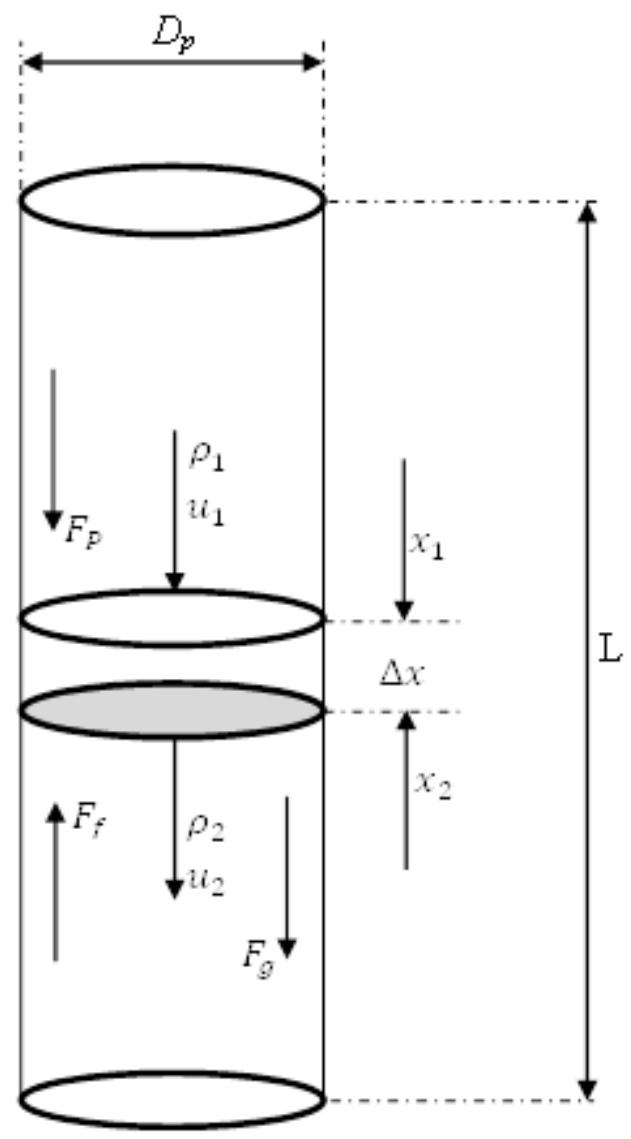

Fig. 1: Schematic representation of a control volume within a vertical pipe and the forces acting on it

Where $F_{P}, F_{f}, F_{g}, \rho$ and $u$ are pressure force, frictional force, gravitational force, fluid density and velocity respectively. $\mathrm{L}, \mathrm{D}_{\mathrm{p}}$ and $\Delta x$ are well depth, diameter and differential control volume.

This study considers a purely vertical injection tube only hence, pipe inclination is unaccounted for. The following simplified assumptions are applied:

- One-dimensional flow in the pipe
- Homogeneous equilibrium fluid flow

- Negligible fluid structure interaction through vibrations

- Constant cross section area of pipe

The assumption of homogeneous equilibrium flow means that all phases are at mechanical and thermal equilibrium (i.e. phases are flowing with same velocity and temperature) hence the three conservation equations should be applied for the fluid mixture. Although, in practice usually the vapour phase travels faster than the liquid phase, the HEM model has been investigated proven to have an acceptable accuracy in many practical applications.

The following gives a detailed account of the HEM model employed for the simulation of the time-dependent flow of $\mathrm{CO}_{2}$ in injection wells. The system of four partial differential equations for the $\mathrm{CO}_{2}$ liquid/gas mixture, to be solved in the well tubing, can be written in the well-known conservative form as follows:

$$
\frac{\partial}{\partial t} \boldsymbol{Q}+\frac{\partial}{\partial x} \boldsymbol{F}(\boldsymbol{Q})=\boldsymbol{S}_{\mathbf{1}}+\boldsymbol{S}_{\mathbf{2}}
$$

where

$$
\begin{aligned}
\boldsymbol{Q}=\left(\begin{array}{c}
\rho A \\
\rho u A \\
\rho E A \\
A
\end{array}\right), & \boldsymbol{F}(\boldsymbol{Q}) \\
& =\left(\begin{array}{c}
\rho u A \\
\rho u^{2} A+A P \\
\rho u H A \\
0
\end{array}\right), \boldsymbol{S}_{1} \\
& \left.=\left(\begin{array}{c}
0 \\
P \frac{\partial A}{\partial x} \\
0 \\
0
\end{array}\right), \quad \begin{array}{c}
\boldsymbol{S}_{2} \\
A(F+\rho \beta g) \\
A(F u+\rho u \beta g+q) \\
0
\end{array}\right)
\end{aligned}
$$

In the above, the first three equations correspond to mass, momentum, and energy conservation, respectively. The fourth equation describes the fact that the cross-sectional area 
$A$ is, at any location along the well, constant in time, but might vary along the depth of the well. Moreover, $u$ and $\rho$ are the mixture velocity and density, respectively. $P$ is the mixture pressure, while $E$ and $H$ represent the specific total energy and total enthalpy of the mixture, respectively. They are defined as:

$$
\begin{gathered}
E=e+\frac{1}{2} u^{2} \\
H=E+\frac{P}{\rho}
\end{gathered}
$$

where $e$ is the specific internal energy. In addition, $x$ denotes the space coordinate, $t$ the time, $F$ the viscous friction force, $q$ the heat flux, and $g$ the gravitational acceleration. In the case of the HEM, the assumption of mechanical equilibrium, i.e. no phase slip, is retained.

The system of partial differential Eq. (2) is an extension of the work previously done in (Curtis M. Oldenburg, 2007), (Celia \& Nordbotten, 2009), by accounting for both a variable cross-sectional area and additional source terms. By analysing in more detail the various source terms appearing on the righthand side of Eq. (2).

The frictional loss $F$ in Eq. (2) can be expressed as

$$
F=-f_{w} \frac{\rho u^{2}}{D_{p}}
$$

where $f_{w}$ is the Fanning friction factor, calculated using Chen's correlation (Chen, 1979), and $D_{p}$ is the internal diameter of the pipe.

The gravitational term includes

$$
\beta=\rho g \sin \theta
$$

which accounts for the possible well deviation.

In Eq. (2) the source term $Q$ accounts for the heat exchange between the fluid and the well wall. The corresponding heat transfer coefficient $\eta$ is calculated using the wellknown Dittus-Boelter correlation (Dittus \& Boelter, 1930):

$$
\eta=0.023 \operatorname{Re}^{0.8} \operatorname{Pr}^{0.4} \frac{k}{D_{p}}
$$

where $k, R e$ and $P r$ are the thermal conductivity, Reynold's number and Prandtl's number for the fluid. The heat exchanged between the fluid and the wall is calculated using the following formula:

$$
q=\frac{4}{D_{p}} \eta\left(T_{w}-T\right)
$$

$T_{w}$ and $T$ are the temperatures of the fluid and of the wall, respectively. Note that $T_{w}=$ $T_{w}(x, t)$, i.e. $T_{w}$ is not assumed constant, but variable with time and space.

\subsection{Boundary conditions}

In order to close the conservation Eq. (2), suitable boundary conditions must be specified. In this study, the boundary conditions are implemented by introducing 'ghost cells' on both ends of the computational domain, representing the wellhead and bottom-hole.

\subsubsection{Top of the well}

At the wellhead, Fig. 2 is a schematic representation of the flow through the wellbore. As can be seen in Fig. 2, $\mathrm{CO}_{2}$ is injected into the well at the top and exit at the bottom into the reservoir. The injection strings are tapered and narrower going down the well. This allows the rapid injection of $\mathrm{CO}_{2}$ and minimises the pressure drop along the wellbore. The development of the required inlet boundary condition for simulating $\mathrm{CO}_{2}$ injection is detailed below. 


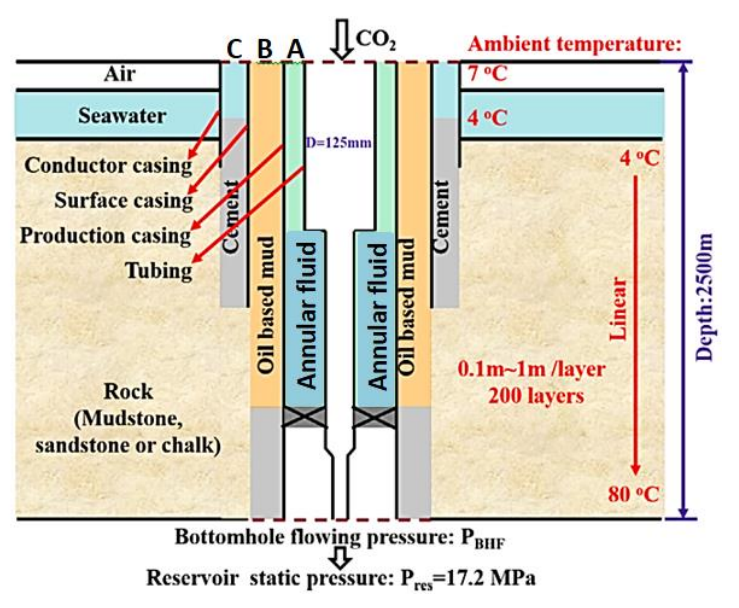

Figure 2: Schematic diagram of the Goldeneye $\mathrm{CO}_{2}$ injection well ( $\mathrm{Li}$ et al., 2015)

Injection of high pressure $\mathrm{CO}_{2}$ into a low pressure well is similar to pipeline depressurisation due to a puncture or rupture. As such, the vapour and liquid phases are dispersed at the well inlet due to high velocity. Given the above, the HEM assumption is applied in the ghost cell at the well inlet and the flow is assumed to be isentropic. As a result, the conservation equations are rewritten as $(\mathrm{K} \mathrm{W}$ Thompson, 1990; Kevin W. Thompson, 1987):

$$
\begin{aligned}
& \frac{\partial \rho}{\partial t}+\frac{1}{c^{2}}\left[\zeta_{2}+\frac{1}{2}\left(\zeta_{3}+\zeta_{1}\right)\right]=0 \\
& \frac{\partial p}{\partial t}+\frac{1}{2}\left[\zeta_{3}+\zeta_{1}\right]=0 \\
& \frac{\partial u}{\partial t}+\frac{1}{2 \rho c}\left[\zeta_{3}-\zeta_{1}\right]-g=0
\end{aligned}
$$

Where, $\zeta$ is referred to as the wave amplitude, for which the generic expressions are given by:

$$
\begin{aligned}
& \zeta_{1}=(u-c)\left\{\frac{\partial p}{\partial x}-\rho c \frac{\partial u}{\partial x}\right\} \\
& \zeta_{2}=0 \\
& \zeta_{3}=(u+c)\left\{\frac{\partial p}{\partial x}+\rho c \frac{\partial u}{\partial x}\right\}
\end{aligned}
$$

$\zeta_{2}$ describes the inflow entropy, so setting $\zeta_{2}=0$ states that the inflow entropy is constant in the $x$-direction. Following (K W Thompson, 1990), modifications to Eqs. (12) and (13) may be required at the flow boundaries. In this case, $\zeta_{1}$ and $\zeta_{3}$ have to be specified in accordant with the flow acceleration through the variable flow areas (i.e. from the injection pipeline into the wellhead).

From Eqs. (9) and (11), the following can be derived for $\zeta_{1}$ and $\zeta_{3}$ :

$$
\begin{aligned}
& \zeta_{1}=\frac{1}{(u-c)}\left\{2 \rho c^{2} g \frac{\partial \dot{m}}{\partial t}-(u+c) \zeta_{3}\right\} \\
& \zeta_{3}=\frac{1}{(u+c)}\left\{2 \rho c^{2} g \frac{\partial \dot{m}}{\partial t}-(u-c) \zeta_{1}\right\}
\end{aligned}
$$

Where $\dot{m}=\rho u$ and its derivative with respect to time is approximated by:

$$
\frac{\partial \dot{m}}{\partial t}=\frac{1}{\Delta t}\left[\left.\dot{m}\right|_{n}-\left.\dot{m}\right|_{n-1}\right]
$$

where the subscripts, $n-1$ and $n$ respectively denote the previous and current time-steps.

Finally, Eqs. (9) to (11) can now be readily solved for a complete description of the flow conditions in the ghost cell at the wellhead.

\subsubsection{Bottom of the well}

The boundary condition at the bottom of the well is described using an empirical pressureflow relationship derived from reservoir properties (Xiaolu Li et al., 2015; Shell, 2015):

$$
\tilde{A}+\tilde{B} \times M+\tilde{C} \times M^{2}=P_{B H P}^{2}-P_{\text {res }}^{2}
$$

where

$\tilde{A}$ is the minimum pressure required for the flow to start from the well into the reservoir, $\mathrm{Pa}$ $\mathrm{s} / \mathrm{kg}$ (see Table 1)

$\tilde{B}$ and $\tilde{C}$ are site-specific dimensional constants, Pa.s/kg (see Table 1) 
$M$ is the instantaneous mass flow rate at the bottom-hole, $\mathrm{kg} / \mathrm{s}$

$P_{B H P}$ is the instantaneous bottom-hole pressure, bar and

$P_{r e s}$ is the reservoir static pressure, bar.

The right hand side of Eq. (17) represent the pressure differential between the bottom of the well and the reservoir. Significantly, when $P_{B H P}^{2}>P_{r e s}^{2}$ there is injection into the reservoir whereas when $P_{B H P}^{2}<P_{r e s}^{2}$ there is a backflow or blowout. In other words, the boundary condition at the bottom of the well can be discretely utilised to satisfy both injection and blowout cases. In describing the relationship between the reservoir and the bottom of the well, Eq. (17) represents a more sophisticated condition than a standard, linear correlation between the bottom-hole pressure and the flow rate.

\section{Numerical method and injection well $\mathrm{CO}_{2}$ inlet conditions}

In this study, an effective model based on the Finite Volume Method (FVM), incorporating a conservative Godunov type finite-difference scheme (Godunov 1959, Radvogin et al. 2011, Cumber et al. 1994) is used. The FVM is well-established and thoroughly validated CFD technique. In essence, the methodology involves the integration of the fluid flow equations over the entire control volumes of the solution domain and then accurate calculation of the fluxes through the boundaries of the computed cells.

For the purpose of numerical solution of the governing equations they are written in a vector form (Toro 2010):

$$
\frac{\partial \vec{Q}}{\partial t}+\frac{\partial \vec{f}}{\partial z}=\vec{S}
$$

where

$$
\vec{Q}=(\rho, \rho u, \rho e)^{T},
$$

$$
\begin{gathered}
\vec{F}=\left(\rho u, \quad\left(\rho u^{2}+P\right)\right. \\
\left.u\left(\rho u e+\rho u^{2}+P\right)\right)^{T} \\
\vec{S}=\left(S^{m}, \quad S^{m o m}, S^{e}\right)^{T}
\end{gathered}
$$

$\vec{Q}, \vec{F}$ and $\vec{S}$ are the vectors of conserved variables, fluxes and source terms respectively. The source terms $S^{m}, S^{m o m}$ and $S^{e}$ describe the effects of mass, momentum and energy exchange between the fluid and its surrounding respectively, as well as friction and heat exchange at the pipe wall.

\subsection{Model Validation}

The model relevance and applicability to real-world injection project is validated using Ketzin pilot site experimental data. The model predictions are closely in agreement with the real-life $\mathrm{CO}_{2}$ injection scenario.

$\mathrm{CO}_{2}$ injection well initial and boundary conditions for Ketzin pilot site Brandenburg, Germany obtained from Möller et al, (2014) employed for the model validation are:

- $\mathrm{CO}_{2}$ inlet pressure $57 \mathrm{bar}$, temperatures $10{ }^{\circ} \mathrm{C}$ and $20{ }^{\circ} \mathrm{C}$, and injection mass flow rate $0.41 \mathrm{~kg} / \mathrm{s}$

- Initial wellhead pressure 48 bar and temperature $10{ }^{\circ} \mathrm{C}$,

- Total well depth 550m; 0.0889m internal diameter

- Initial bottom-hole pressure 68 bar and temperature $33^{\circ} \mathrm{C}$,

As can be seen in Figs. 3 and 4, the simulation results for $10^{\circ} \mathrm{C}$ and $20^{\circ} \mathrm{C}$ injection inlet temperature condition all showed good agreement with the experimental data. The performance of our model in relation to the Ketzin pilot real-world experimental injection project shows it reliability and applicability. 


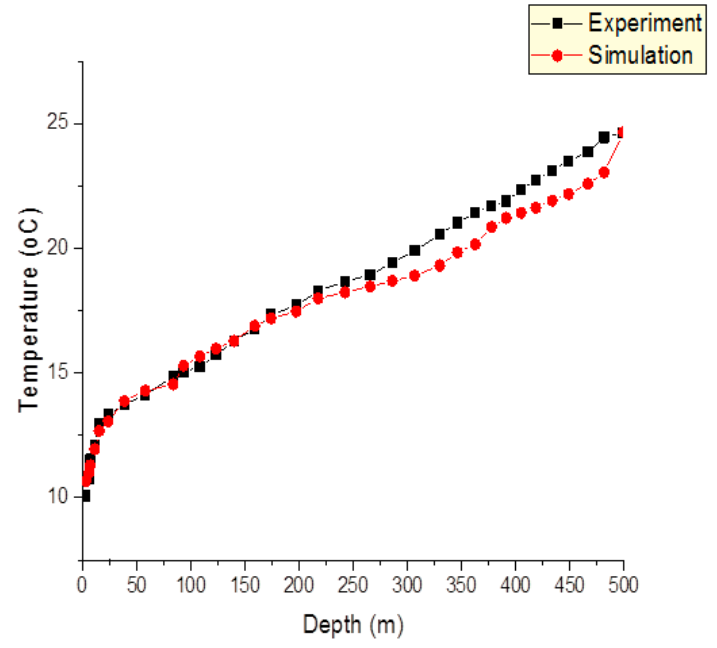

Figure 3: Well temperature profile for $10^{\circ} \mathrm{C}$ inlet $\mathrm{CO}_{2}$ injection temperature

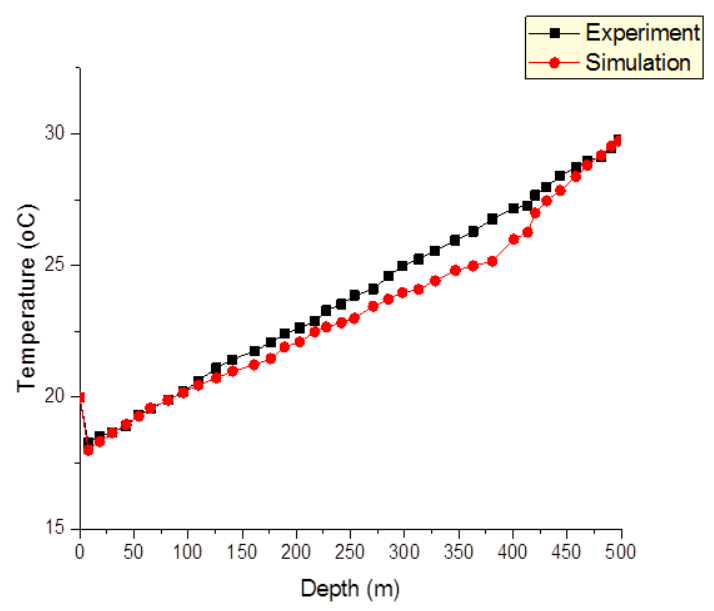

Figure 4: Well temperature profile for $20^{\circ} \mathrm{C}$ inlet $\mathrm{CO}_{2}$ injection temperature

\section{Injection well and $\mathrm{CO}_{2}$ inlet conditions}

The data used in this study obtained from the Peterhead CCS project include the well depth and pressure and temperature profiles, along with the surrounding formation characteristics as presented in (Xiaolu Li et al., 2015; Shell UK, 2015) and reproduced in Table 1. The Peterhead CCS project was proposed to capture one million tonnes of $\mathrm{CO}_{2}$ per annum for 15 years from an existing combined cycle gas turbine located at Peterhead Power Station in Aberdeenshire, Scotland. In the project, the $\mathrm{CO}_{2}$ captured from the Peterhead Power Station would have been transported by pipeline and then injected into the depleted Goldeneye reservoirs. Despite the cancellation of the project funding, useful information was already available, given that the Goldeneye reservoir had been used for extraction of natural gas for many years.

Table 1: Goldeneye injection well and $\mathrm{CO}_{2}$ inlet conditions (Shell UK, 2015)

\begin{tabular}{|c|c|}
\hline Input parameter & Value \\
\hline $\begin{array}{l}\text { Wellhead pressure, } \\
\text { bar }\end{array}$ & 36 \\
\hline $\begin{array}{l}\text { Wellhead } \\
\text { temperature, } \mathrm{K}\end{array}$ & 277 \\
\hline $\begin{array}{l}\text { Bottom-hole } \\
\text { temperature, } \mathrm{K}\end{array}$ & 353 \\
\hline $\begin{array}{l}\text { Well } \\
\text { diameter/depth, m }\end{array}$ & $\begin{array}{l}0-800 \mathrm{~m} \text { depth: } \\
0.125 \mathrm{~m} \\
800-2000 \mathrm{~m} \text { depth: } \\
0.0765 \mathrm{~m} \\
2000-2582 \mathrm{~m} \text { depth: } \\
0.0625 \mathrm{~m}\end{array}$ \\
\hline $\begin{array}{l}\mathrm{CO}_{2} \text { injection mass } \\
\text { flow rate, } \mathrm{kg} / \mathrm{s}\end{array}$ & $\begin{array}{l}3 \text { different cases: } \\
\text { linearly ramped-up } \\
\text { to } 38.5 \mathrm{~kg} / \mathrm{s} \text { in } 5 \\
\text { minutes, } 30 \text { minutes } \\
\text { and } 2 \text { hours }\end{array}$ \\
\hline $\begin{array}{l}\text { Injection tube } \\
\text { diameter, } m\end{array}$ & $0.125 \mathrm{~m}$ \\
\hline $\begin{array}{l}\mathrm{CO}_{2} \text { inlet pressure, } \\
\text { bar }\end{array}$ & 115 \\
\hline $\begin{array}{l}\mathrm{CO}_{2} \text { inlet } \\
\text { temperature, } \mathrm{K}\end{array}$ & 280 \\
\hline Outflow & $\begin{array}{c}\tilde{A}=0 \\
\tilde{B}=1.3478 \times \\
10^{12} \mathrm{~Pa}^{2} \mathrm{~s} / \mathrm{kg} \\
\tilde{C}=2.1592 \times \\
10^{10} \mathrm{~Pa}^{2} \mathrm{~s}^{2} / \mathrm{kg}^{2} \\
P_{\text {res }}=172 \text { bar }\end{array}$ \\
\hline
\end{tabular}


Fig. 5 shows the initial distribution of the pressure and the temperature along the well. Based on this initial pressure and temperature distribution obtained from the Goldeneye $\mathrm{CO}_{2}$ injection well, the $\mathrm{CO}_{2}$ is in the gas phase in the first $400 \mathrm{~m}$ along the well and dense phase within the rest of the well depth. This initial condition is the same for all 3 ramp-up injection cases considered. In particular, this study considers linearly ramped-up injection mass flow rates from 0 to $38.5 \mathrm{~kg} / \mathrm{s}$ in 5 minutes, 30 minutes and 2 hours. The varying ranges of $\mathrm{CO}_{2}$ injection mass flow rate ramped up with time from 0 to $38.5 \mathrm{~kg} / \mathrm{s}$ at $\mathrm{CO}_{2}$ feed pressure of 115 bar employed in this study is essential to understanding the optimum injection ramp-up duration.

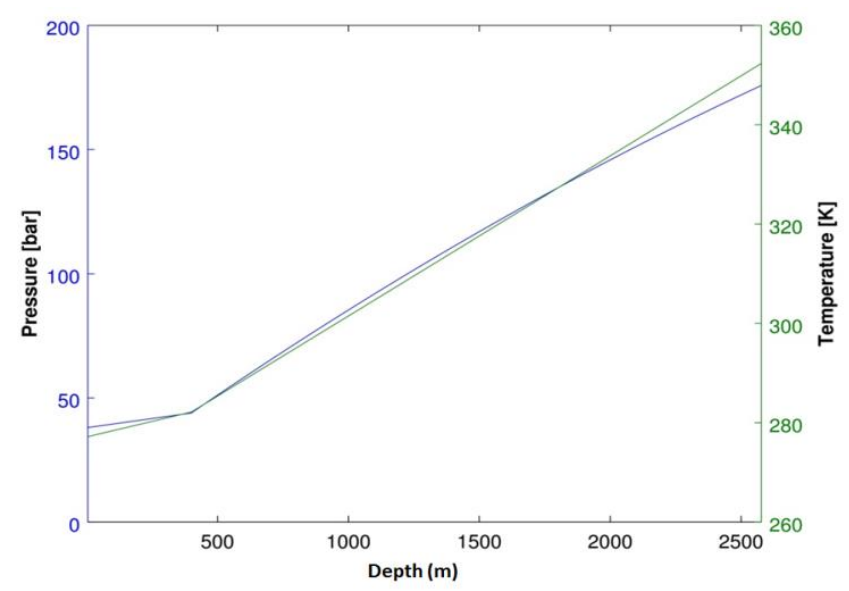

Figure 5: Initial distribution of the pressure and the temperature along the well

\subsection{Thermodynamics}

In this study, the $\mathrm{CO}_{2}$ thermal properties and phase equilibrium data are computed using Reng-Robinson (PR) Equation of State (EoS) (Peng \& Robinson, 1976). PR EoS has been extensively applied and validated in pipeline decompression studies especially for $\mathrm{CO}_{2}$ showing very good agreement with experimental data (see Brown et al, 2013a; Brown et al, 2013b; Mahgerefteh et al, 2012; Martynov et al, Sundara, 2013). The PR EoS has been proven valid and highly useful for both single fluid and multi-component studies hence the validity of this study (see also Hajiw et al, 2018; Henderson et al, 2001; IEAGHG,
2011; Kwak \& Kim, 2017; Mireault et al, 2010; Wang et al, 2011; Wang et al, 2015; Ziabakhsh-Ganji \& Kooi, 2014).

\section{Results and discussion}

The results obtained following the simulation of the transient flow model for the ramp-up injection of $\mathrm{CO}_{2}$ into highly depleted oil/gas fields are presented and discussed in details. Beginning at the top inlet of the injection well down to the bottom outlet into the reservoir, the pressure and temperature profiles are presented. Specifically, the pressure and temperature variations at the top of the well and the corresponding effects along the wellbore can be seen in the profiles.

Figs. 6 to 8 show the variations in pressure with time at the top of the well for 5 mins, 30 mins and $2 \mathrm{hrs}$ ramp-up injection times. The start-up injection data shows a rapid drop in pressure of the incoming $\mathrm{CO}_{2}$ at 115 bar to as low as 36.5 bar. The pressure drops to 74,66 and 36.5 bar corresponding to injection rampup period of 5 mins, 30 mins and $2 \mathrm{hrs}$ respectively. Following the initial pressure is a recovery over the ramp-up duration until a steady state is attained in each case. The pressure recovery is quicker for the fast 5 mins ramp-up case and slower for the 30 mins or 2 hrs ramp-up cases. Consequently a fast rampup during $\mathrm{CO}_{2}$ injection will help minimise the initial pressure drop due to the difference in wellhead pressure and that of incoming $\mathrm{CO}_{2}$ and also enhance a fast recovery after rapid pressure drop. 


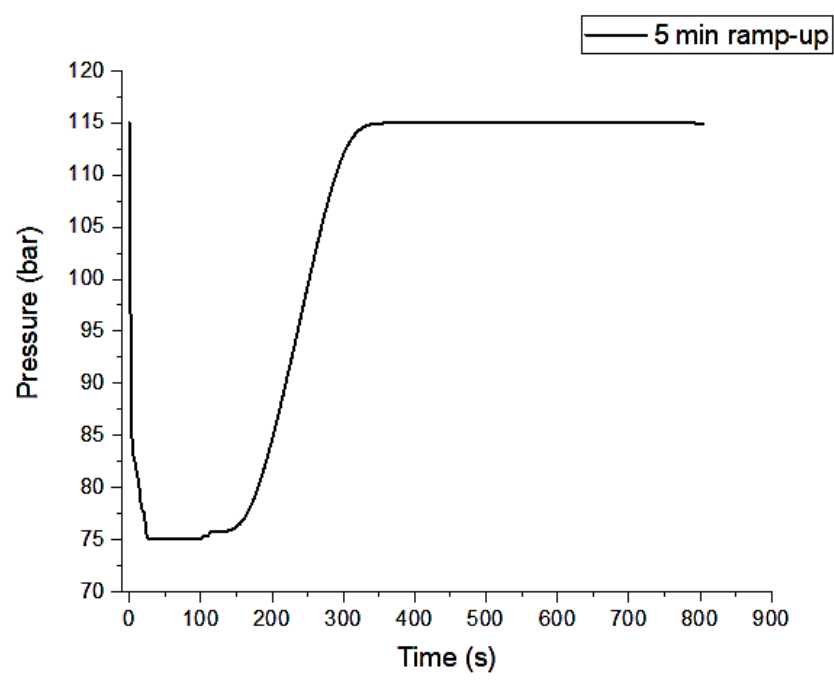

Figure 6: $\mathrm{CO}_{2}$ wellhead pressure variation with time for 5 mins ramp-up injection case

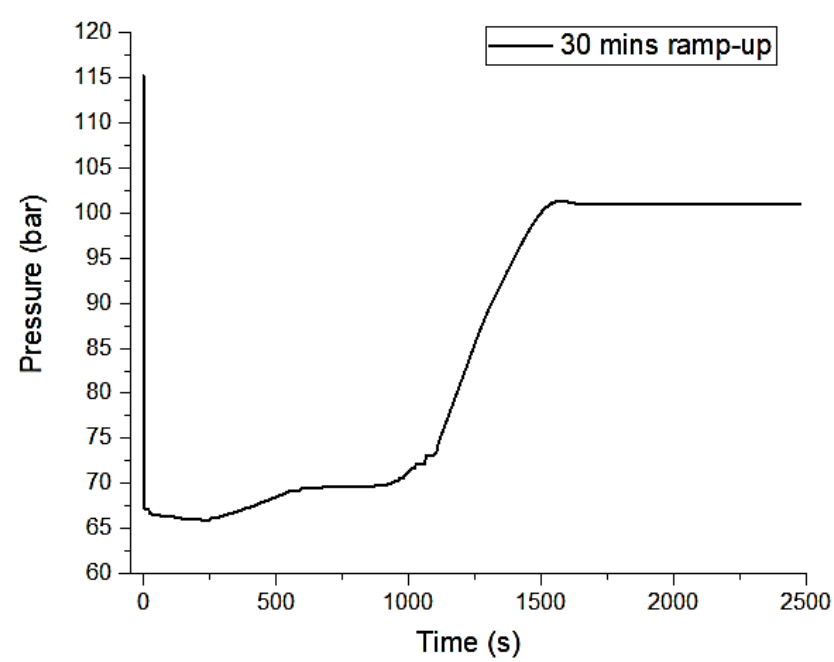

Figure 7: $\mathrm{CO}_{2}$ wellhead pressure variation with time for 30 mins ramp-up injection case

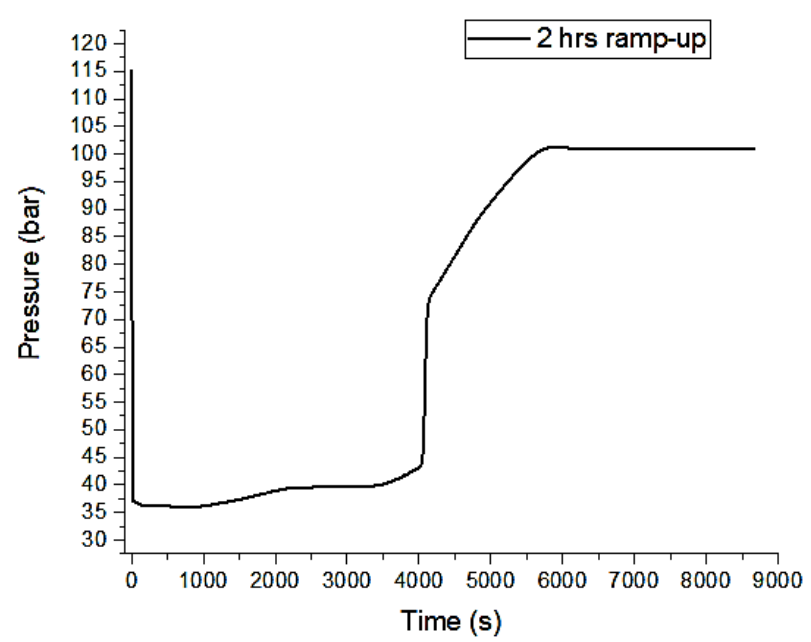

Figure 8: $\mathrm{CO}_{2}$ wellhead pressure variation with time for $2 \mathrm{hrs}$ ramp-up injection case

As can be seen in Fig. 9 where all three ramp-up cases are shown together. The 5 mins ramp-up case predicts a lesser pressure drop and high recovery compared with the other cases of 30 mins and 2 hrs ramp-up. This implies that for best practice a fast ramp-up is recommended to minimise the risk of large pressure drop and a corresponding low temperature. This shows that the injected $\mathrm{CO}_{2}$ undergoes a refrigeration effect caused by the Joule-Thomson expansion.

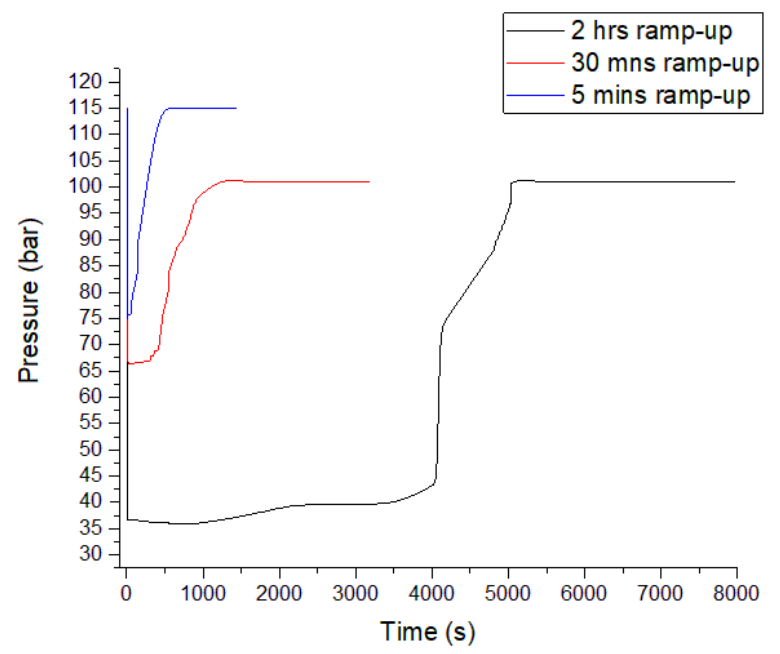

Figure 9: $\mathrm{CO}_{2}$ wellhead pressure profiles for 5 mins, 30 mins and 2 hrs ramp-up injection cases

Figs. 10 to 12 show the variations in temperature with time at the top of the well for 5 mins, 30 mins and 2 hrs ramp-up injection times. The start-up injection data shows a rapid drop in temperature of the incoming $\mathrm{CO}_{2}$ from 
$277 \mathrm{~K}$ to as low $226 \mathrm{~K}$. The temperature drops to 252,238 and $226 \mathrm{~K}$ corresponding to injection ramp-up period of 5 mins, 30 mins and $2 \mathrm{hrs}$ respectively. Following the initial temperature drop is a recovery over the rampup duration until a steady state is attained in each case. The temperature recovery however gets better with increasing ramp-up duration. The predicted steady-state temperatures after recovery for the fast 5 mins ramp-up case and slower for the 30 mins or $2 \mathrm{hrs}$ ramp-up cases are respectively 277, 280 and $303 \mathrm{~K}$. Consequently a fast ramp-up during $\mathrm{CO}_{2}$ startup injection will help minimise this initial temperature drop due to the difference in the pressure at top of the injection well and that of the incoming $\mathrm{CO}_{2}$. Also, in order to enhance a fast recovery after the initial rapid pressure and temperature drop.

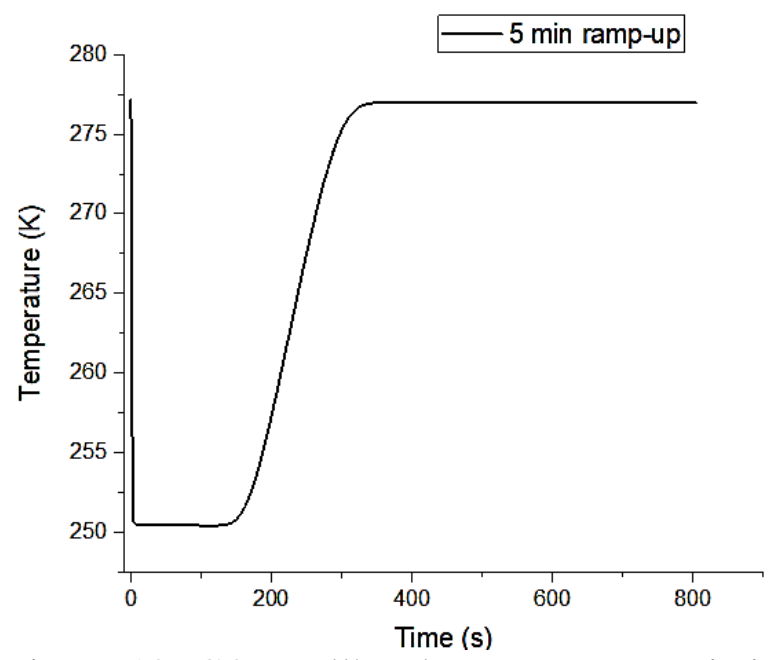

Figure 10: $\mathrm{CO}_{2}$ wellhead temperature variation with time for 5 mins ramp-up injection case

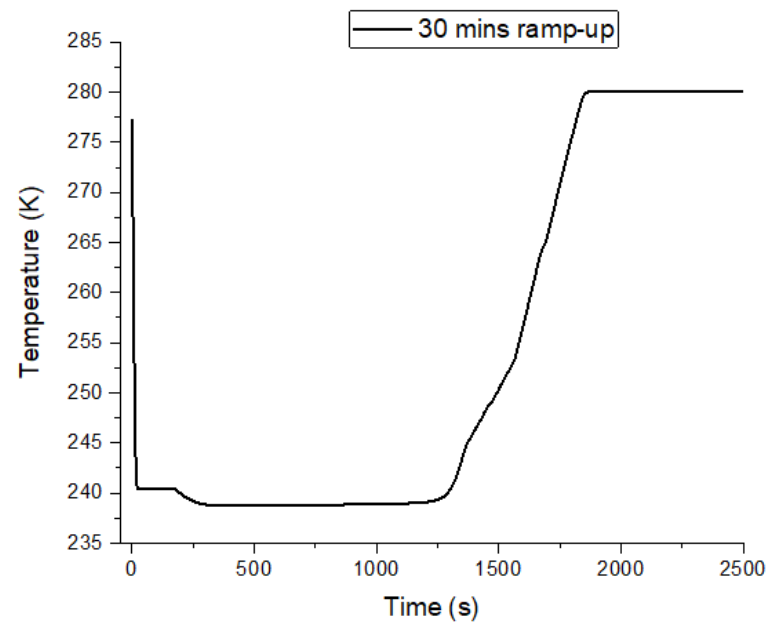

Figure 11: $\mathrm{CO}_{2}$ wellhead temperature variation with time for 30 mins ramp-up injection case

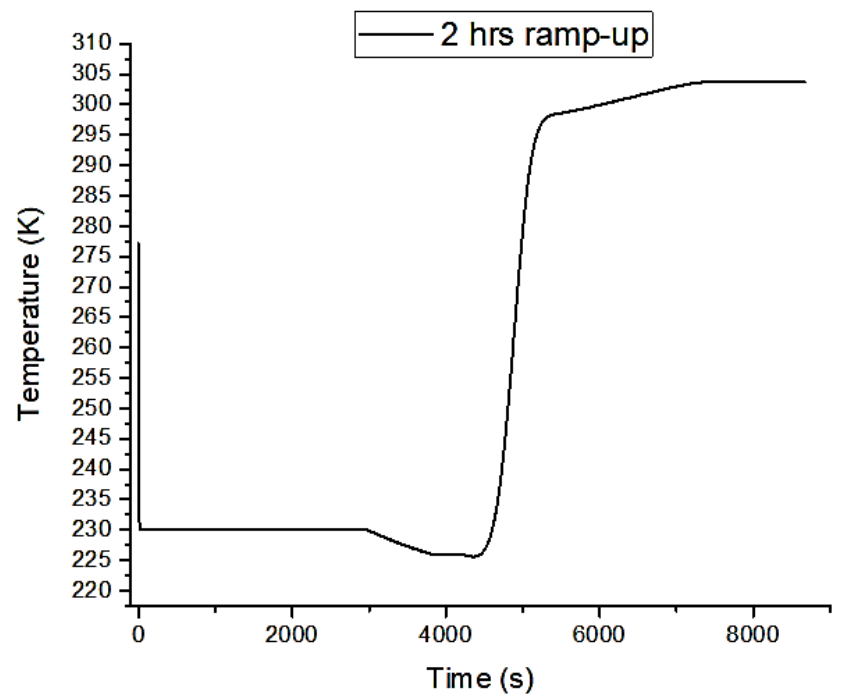

Figure 12: $\mathrm{CO}_{2}$ wellhead temperature variation with time for $2 \mathrm{hrs}$ ramp-up injection case

As can be seen in Fig. 13 where all three ramp-up cases of $\mathrm{CO}_{2}$ wellhead temperature profiles are shown together. The 5 mins rampup case predicts a lesser temperature drop compared with the other cases of 30 mins and 2 hrs ramp-up. This implies that for best practice a fast (5 mins) ramp-up is recommended to minimise the risk of large temperature drop. In simply terms, the fast ramp-up is exposed to a short time refrigeration effect caused by the Joule-Thomson expansion. 


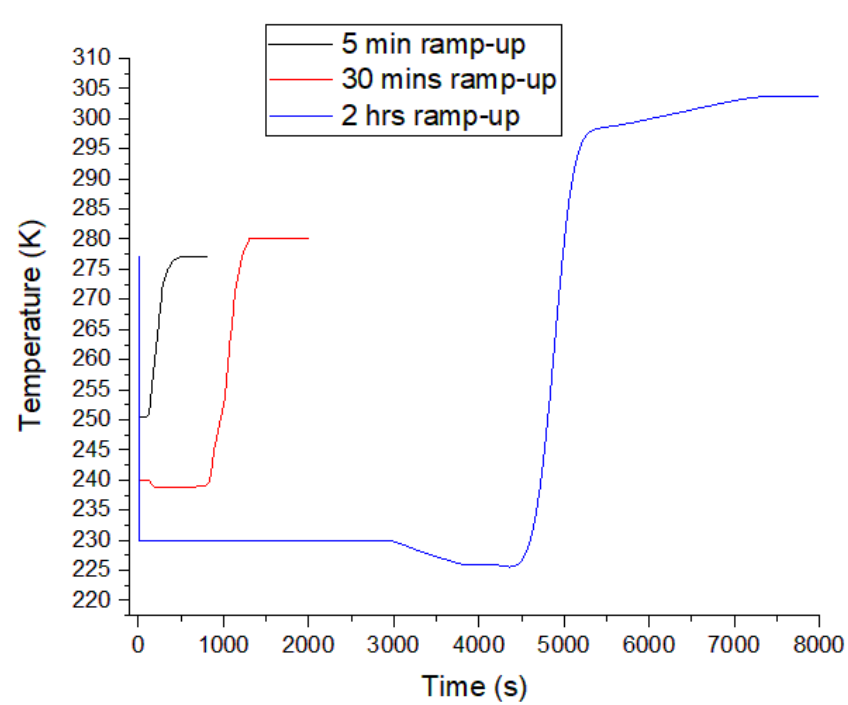

Figure 13: $\mathrm{CO}_{2}$ wellhead temperature profiles for 5 mins, 30 mins and $2 \mathrm{hrs}$ ramp-up injection cases

Figs. 14 and 15 respectively show the corresponding results for the temperature and pressure profiles along the length of the well during the 5 mins ramping up process at different selected time intervals of 10, 100, 200 and 300 seconds. The pressure profiles show continues pressure build up along the wellbore during the 5 mins injection ramp up. On the contrary, the temperature profiles show a significant temperature drop for the 10,100 and $200 \mathrm{~s}$ well profiles in comparison with the initial well temperature profile at $0 \mathrm{~s}$. The well temperature profile at $300 \mathrm{~s}$ shows significant recovery approaching the initial well temperature profile. As can been seen in Fig. 15 the temperature profile along the injection wellbore shows an improve profile as the ramp up injection duration reaches $300 \mathrm{~s}$ compared with the 10, 100 and $200 \mathrm{~s}$ cases. In other words, operating a fast injection ramp-up is recommended to rapidly increase the injection flow rate with time and consequently minimise the drop in temperature along the wellbore.

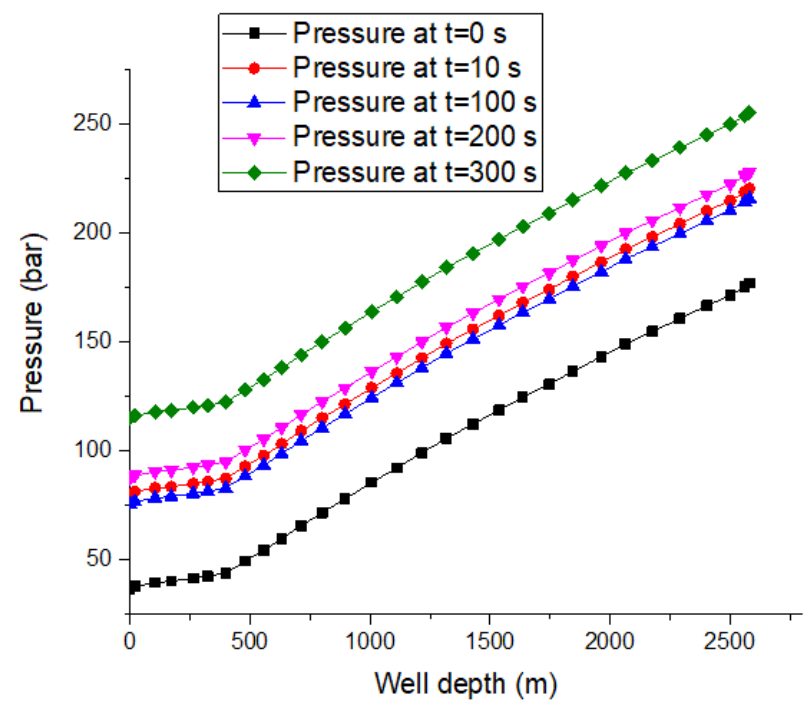

Figure 14: 5 mins ramp-up injection well pressure profiles at varying times

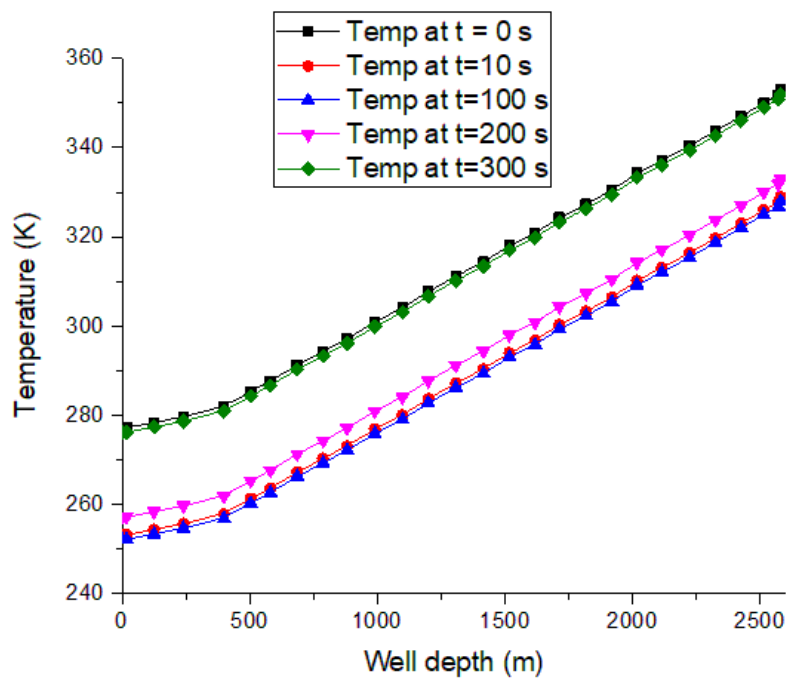

Figure 15: 5 mins ramp-up injection well temperature profiles at varying times

Finally, the current model is briefly compared with OLGA simulation result that Acevedo \& Chopra, (2017) presented in their paper "Influence of phase behaviour in the well design of $\mathrm{CO}_{2}$ injectors".

In Fig. 16, the results of both model simulation indicated low temperature in the top section of the well during the continuous injection period. The reduction in temperature is due to the flashing of the liquid $\mathrm{CO}_{2}$ to gas/liquid $\mathrm{CO}_{2}$ caused by the low reservoir pressure. During transient operations (closing-in and re-starting injection operations), a temperature drop is observed at the top of the well for a short period of time. The sequence of steady state 
injection, closing-in operation (30 minutes), closed-in time (10minutes), and starting-up operation (30minutes) for the low reservoir pressure case was simulated using OLGA (Acevedo \& Chopra, 2017) and our model, see Figure 16. As can be seen the current model predicted slightly lower $\mathrm{CO}_{2}$ temperatures than OLGA. This is likely due to the inconsistency of the Peng-Robinson Equation of State employed in the current study for the prediction of $\mathrm{CO}_{2}$ thermodynamics properties.

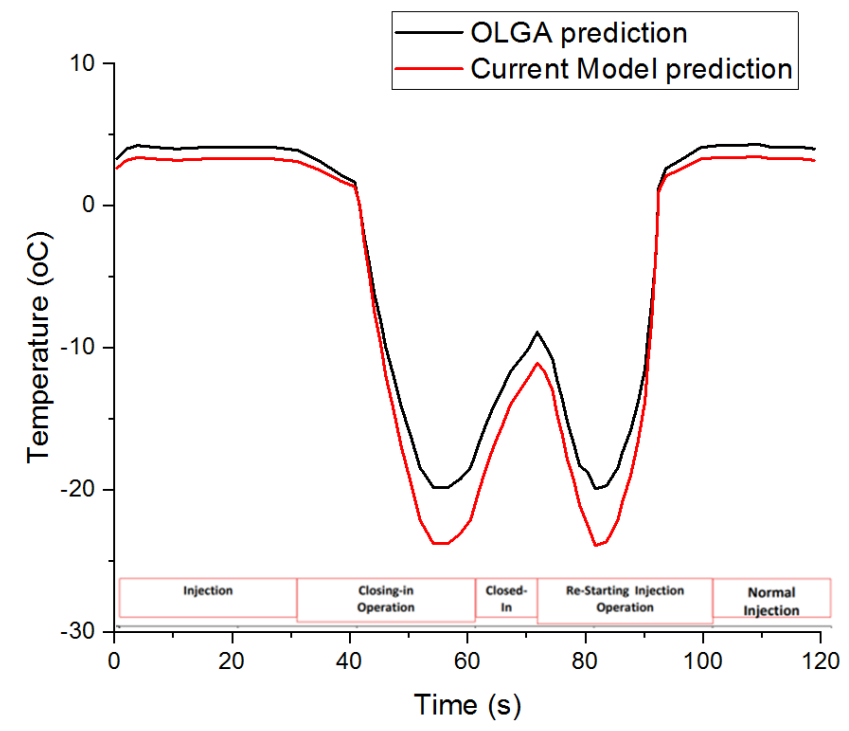

Figure 16: Comparison of temperature profiles at the top of the well sequence of closing and opening a $\mathrm{CO}_{2}$ injector well

\section{Conclusions and recommendations}

This study has led to the development and testing of a rigorous model for the simulation of the highly-transient multi-phase flow phenomena taking place in wellbores during the start-up injection of high pressure $\mathrm{CO}_{2}$ into depleted gas fields. In practice, the model developed can serve as a valuable tool for the development of optimal injection strategies and best-practice guidelines for the minimisation of the risks associated with the start-up injection of $\mathrm{CO}_{2}$ into depleted gas fields. In order to assess key parameters having the greatest impact on the transient flow of $\mathrm{CO}_{2}$ in the injection well, sensitivity analysis has been performed over several parameters by different authors. However, varying injection ramping up times considered in this study has never been studied in previous publications. As such, this study introduces a new area of consideration and gives a clearer insight on the effects of $\mathrm{CO}_{2}$ injection ramp-up times on the wellbore pressure and temperature profiles. The importance of investigating the injection flow rates ramp-up times is driven by the need for the development of optimal injection strategies and best-practice guidelines for the minimisation of the risks associated with the process.

Based on the application of the model developed in this work to realistic test cases involving the ramping up of $\mathrm{CO}_{2}$ injection flow rates from 0 to $38.5 \mathrm{~kg} / \mathrm{s}$ into the Goldeneye depleted reservoir in the North Sea following fast (5 mins), medium (30 mins) and slow (2 hrs) injection ramp-up times, the main findings and recommendations of this work can be summarised as follows:

- The degree of cooling along the injection well becomes less severe with a decrease in the injection ramp-up duration. In other words, operating a fast start-up injection ramp-up is recommended (i.e. between 5 and 30 mins) rather than a slower one (over 2 hrs). This is due the limited exposure time to the refrigeration effect caused by the JT expansion on the injected $\mathrm{CO}_{2}$.

- The formation of ice during the ramp up injection process is likely, given that in all cases considered the minimum fluid temperature falls well below $0{ }^{\circ} \mathrm{C}$ at the top of the well. This poses the risk of ice formation and ultimately well blockage should a sufficient quantity of water be present. Thus, for this case study injecting $\mathrm{CO}_{2}$ at temperatures well above $290 \mathrm{~K}$ at flow rate ramp-up duration of 5 mins will be best practice to minimise this risk.

- The minimum simulated $\mathrm{CO}_{2}$ temperature and the corresponding pressure predicted at the top of well during the start-up injection flow rate 
ramp-up process are close to the ranges where $\mathrm{CO}_{2}$ hydrates formation would be expected. The ideal hydrate formation conditions are pressures and temperatures below $273.15 \mathrm{~K}$ and 12.56 bar however, tiny molecules of $\mathrm{CO}_{2}$ hydrates begin formation at pressures and temperatures just below $283 \mathrm{~K}$ and 49.99 bar (Circone et al., 2003; Yang et al., 2012).

- Given the observed relatively large drop in temperature at the top of the well especially for the $2 \mathrm{hrs}$ injection flow ramp-up case, well failure due to thermal stress shocking (i.e. as a result of the temperature gradient between inner and outer layers of the steel casing) during the injection process could be a real risk. This could lead to a brittle fracture situation should the temperature drops below $-30{ }^{\circ} \mathrm{C}$. The design temperature at which steel becomes highly brittle according the Stainless Steel Information Centre of North America. Hence, the risk of injection system failure due to thermal stress shocking of the steel casing can be avoided by keeping to a fast or medium injection flow ramp-up.

Finally, it is critically important to bear in mind that the above conclusions are not universal. On the contrary, they are only based on the case study investigated. Each injection scenario must be individually examined in order to determine the likely risks. In this paper, the necessary computational tool is developed to make such risks assessment.

\section{References}

Acevedo, L., \& Chopra, A. (2017). Influence of Phase Behaviour in the Well Design of CO2Injectors. Energy Procedia, 114(November 2016), 5083-5099. http://doi.org/10.1016/j.egypro.2017.03.16 63

André, L., Audigane, P., Azaroual, M., \& Menjoz, A. (2007). Numerical modeling of fluid-rock chemical interactions at the supercritical $\mathrm{CO} 2$-liquid interface during $\mathrm{CO} 2$ injection into a carbonate reservoir, the Dogger aquifer (Paris Basin, France). Energy Conversion and Management, 48(6), 1782-1797.

http://doi.org/10.1016/j.enconman.2007.0 1.006

Böser, W., \& Belfroid, S. (2013). Flow Assurance Study. Energy Procedia, 37, 3018-3030. http://doi.org/10.1016/j.egypro.2013.06.18 8

Brown, S., Beck, J., Mahgerefteh, H., \& Fraga, E. S. (2013). Global sensitivity analysis of the impact of impurities on $\mathrm{CO} 2$ pipeline failure. Reliability Engineering and System Safety, 115, 43-54. http://doi.org/10.1016/j.ress.2013.02.006

Brown, S., Martynov, S., Mahgerefteh, H., \& Proust, C. (2013). A homogeneous relaxation flow model for the full bore rupture of dense phase $\mathrm{CO} 2$ pipelines. International Journal of Greenhouse Gas Control, 17, 349-356. http://doi.org/10.1016/j.ijggc.2013.05.020

Celia, M. a., \& Nordbotten, J. M. (2009). Practical modeling approaches for geological storage of carbon dioxide. Ground Water, 47(5), 627-638. http://doi.org/10.1111/j.17456584.2009.00590.x

Chen, N. H. (1979). An Explicit Equation for Friction Factor in Pipe. Industrial \& Engineering Chemistry Fundamentals, 18(3), 296-297. http://doi.org/10.1021/i160071a019

Circone, S., Stern, L. a., Kirby, S. H., Durham, W. B., Chakoumakos, B. C., Rawn, C. J., ... Ishii, Y. (2003). $\mathrm{CO}_{2}$ Hydrate: Synthesis, Composition, Structure, Dissociation Behavior, and a Comparison to Structure I CH ${ }_{4}$ Hydrate. The Journal of Physical Chemistry B, 
107(23), 5529-5539.

http://doi.org/10.1021/jp027391j

\section{COP 21. (2015). COP 21 Paris France}

Sustainable Innovation Forum 2015

working with UNEP.

Cotton, A., Gray, L., \& Maas, W. (2017). Learnings from the Shell Peterhead CCS Project Front End Engineering Design. Energy Procedia, 114, 5663-5670. http://doi.org/10.1016/J.EGYPRO.2017.0 3.1705

De Koeijer, G., Hammer, M., Drescher, M., \& Held, R. (2014). Need for experiments on shut-ins and depressurizations in CO2injection wells. In Energy Procedia (Vol. 63, pp. 3022-3029). Elsevier B.V. http://doi.org/10.1016/j.egypro.2014.11.32 5

Dennis Gammer. (2016). Reducing the cost of CCS - Developments in Capture Plant... The ETI. Retrieved from http://www.eti.co.uk/insights/reducingthe-cost-of-ccs-developments-in-captureplant-technology/

Dittus, F. W., \& Boelter, L. M. K. (1930). Heat Transfer in Automobile Radiators, 2, 443.

Goodarzi, S., Settari, A., Zoback, M. D., \& Keith, D. (2010). Thermal Aspects of Geomechanics and Induced Fracturing in $\mathrm{CO} 2$ Injection With Application to $\mathrm{CO} 2$ Sequestration in Ohio River Valley. SPE International Conference on $\mathrm{CO} 2$ Capture, Storage, and Utilization. Society of Petroleum Engineers. http://doi.org/10.2118/139706-MS

Hajiw, M., Corvisier, J., Ahmar, E. El, \& Coquelet, C. (2018). Impact of impurities on $\mathrm{CO} 2$ storage in saline aquifers: Modelling of gases solubility in water. International Journal of Greenhouse Gas Control, 68, 247-255. http://doi.org/10.1016/J.IJGGC.2017.11.0 17
Hannis, S., Pearce, J., Chadwick, A., \& Kirk, K. (2017). IEAGHG Technical Report January 2017 Case Studies of CO 2 Storage in Depleted Oil and Gas Fields, (January).

Henderson, N., de Oliveira, J. R., Souto, H. P. A., \& Marques, R. P. (2001). Modeling and Analysis of the Isothermal Flash Problem and Its Calculation with the Simulated Annealing Algorithm. Industrial \& Engineering Chemistry Research, 40(25), 6028-6038. http://doi.org/10.1021/ie001151d

Hughes, D. S. (2009). Carbon storage in depleted gas fields: Key challenges. Energy Procedia, 1(1), 3007-3014. http://doi.org/10.1016/j.egypro.2009.02.07 8

IEAGHG. (2015). Carbon Capture and Storage Cluster Projects: Review and Future Opportunities, (April).

IEAGHG (International Energy Agency greenhouse gas emissions). (2011). Effects of Impurities on Geological Storage of CO2, (June), Report: 2011/04.

Jiang, P., Li, X., Xu, R., Wang, Y., Chen, M., Wang, H., \& Ruan, B. (2014). Thermal modeling of $\mathrm{CO} 2$ in the injection well and reservoir at the Ordos CCS demonstration project, China. International Journal of Greenhouse Gas Control, 23, 135-146. http://doi.org/10.1016/j.ijggc.2014.01.011

Kwak, D.-H., \& Kim, J.-K. (2017). Technoeconomic evaluation of $\mathrm{CO} 2$ enhanced oil recovery (EOR) with the optimization of $\mathrm{CO} 2$ supply. International Journal of Greenhouse Gas Control, 58, 169-184. http://doi.org/10.1016/j.ijggc.2017.01.002

Li, X., Li, G., Wang, H., Tian, S., Song, X., Lu, P., \& Wang, M. (2017). International Journal of Greenhouse Gas Control A unified model for wellbore flow and heat transfer in pure $\mathrm{CO} 2$ injection for 
geological sequestration, EOR and fracturing operations. International Journal of Greenhouse Gas Control, 57, 102-115.

http://doi.org/10.1016/j.ijggc.2016.11.030

Li, X., Xu, R., Wei, L., \& Jiang, P. (2015). Modeling of wellbore dynamics of a $\mathrm{CO} 2$ injector during transient well shut-in and start-up operations. International Journal of Greenhouse Gas Control, 42, 602-614. http://doi.org/10.1016/j.ijggc.2015.09.016

Lindeberg, E. (2011). Modelling pressure and temperature profile in a $\mathrm{CO} 2$ injection well. Energy Procedia, 4, 3935-3941. http://doi.org/10.1016/j.egypro.2011.02.33 2

Linga, G., \& Lund, H. (2016). A two-fluid model for vertical flow applied to $\mathrm{CO} 2$ injection wells. International Journal of Greenhouse Gas Control, 51, 71-80. http://doi.org/10.1016/j.ijggc.2016.05.009

Lu, M., \& Connell, L. D. (2008). Nonisothermal flow of carbon dioxide in injection wells during geological storage. International Journal of Greenhouse Gas Control, 2(2), 248-258. http://doi.org/10.1016/S17505836(07)00114-4

Lu, M., \& Connell, L. D. (2014). The transient behaviour of $\mathrm{CO} 2$ flow with phase transition in injection wells during geological storage - Application to a case study. Journal of Petroleum Science and Engineering, 124, 7-18. http://doi.org/10.1016/j.petrol.2014.09.02 4

Mahgerefteh, H., Brown, S., \& Denton, G. (2012). Modelling the impact of stream impurities on ductile fractures in $\mathrm{CO} 2$ pipelines. Chemical Engineering Science, 74, 200-210.

http://doi.org/10.1016/j.ces.2012.02.037
Martynov, S., Brown, S., Mahgerefteh, H., \& Sundara, V. (2013). Modelling choked flow for $\mathrm{CO} 2$ from the dense phase to below the triple point. International Journal of Greenhouse Gas Control, 19, 552-558.

http://doi.org/10.1016/j.ijggc.2013.10.005

Mireault, R. A., Stocker, R., Dunn, D. W., \& Pooladi-Darvish, M. (2010). Wellbore Dynamics of Acid Gas Injection Well Operation. Society of Petroleum Engineers. http://doi.org/10.2118/135455MS

Möller, F., Liebscher, A., Martens, S., Schmidt-Hattenberger, C., \& Streibel, M. (2014). Injection of CO2 at ambient temperature conditions - Pressure and temperature results of the "cold injection" experiment at the Ketzin pilot site. In Energy Procedia (Vol. 63, pp. 62896297). http://doi.org/10.1016/j.egypro.2014.11.66 0

Munkejord, S. T., Hammer, M., \& L??vseth, S. W. (2016). CO2 transport: Data and models - A review. Applied Energy, 169, 499-523.

http://doi.org/10.1016/j.apenergy.2016.01. 100

Nordbotten, J. M., Celia, M. A., \& Bachu, S. (2005). Injection and storage of $\mathrm{CO} 2$ in deep saline aquifers: Analytical solution for $\mathrm{CO} 2$ plume evolution during injection. Transport in Porous Media, 58(3), 339360. http://doi.org/10.1007/s11242-0040670-9

Oldenburg, C. M. (2007). Joule-Thomson cooling due to $\mathrm{CO} 2$ injection into natural gas reservoirs. Energy Conversion and Management, 48(6), 1808-1815. http://doi.org/10.1016/j.enconman.2007.0 1.010

Oldenburg, C. M., Pruess, K., \& Benson, S. M. (2001). Process modeling of $\mathrm{CO} 2$ 
injection into natural gas reservoirs for carbon sequestration and enhanced gas recovery. Energy \& Fuels, 15(2), 293298. http://doi.org/Doi

10.1021/Ef000247h

Pan, L., Webb, S. W., \& Oldenburg, C. M. (2011). Analytical solution for two-phase flow in a wellbore using the drift-flux model. Advances in Water Resources, 34(12), 1656-1665.

http://doi.org/10.1016/j.advwatres.2011.0 8.009

Paterson, L., Lu, M., Connell, L., \& EnnisKing, J. (2008). Numerical Modeling of Pressure and Temperature Profiles Including Phase Transitions in Carbon Dioxide Wells. SPE Annual Technical Conference and Exhibition, Denver, Colorado USA, Sept 21-24. Society of Petroleum Engineers. http://doi.org/10.2118/115946-MS

Peng, D.-Y., \& Robinson, D. B. (1976). A New Two-Constant Equation of State. Industrial \& Engineering Chemistry Fundamentals, 15(1), 59-64. http://doi.org/10.1021/i160057a011

Ruan, B., Xu, R., Wei, L., Ouyang, X., Luo, F., \& Jiang, P. (2013). Flow and thermal modeling of $\mathrm{CO} 2$ in injection well during geological sequestration. International Journal of Greenhouse Gas Control, 19, 271-280. http://doi.org/10.1016/j.ijggc.2013.09.006

Samuel, R. J., \& Mahgerefteh, H. (2017). Transient Flow Modelling of Start-up CO2 Injection into Highly-Depleted Oil/Gas Fields. International Journal of Chemical Engineering and Applications, 8(5), 319-326.

http://doi.org/10.18178/ijcea.2017.8.5.677

Sanchez Fernandez, E., Naylor, M., Lucquiaud, M., Wetenhall, B., Aghajani, H., Race, J., \& Chalmers, H. (2016). Impacts of geological store uncertainties on the design and operation of flexible CCS offshore pipeline infrastructure.

International Journal of Greenhouse Gas Control, 52, 139-154.

http://doi.org/10.1016/j.ijggc.2016.06.005

Shell. (2015). Peterhead CCS Project.

Shell UK, T. R. (2015). Peterhead CCS Project.

Thompson, K. W. (1987). Time dependent boundary conditions for hyperbolic systems. Journal of Computational Physics, 68(1), 1-24. http://doi.org/10.1016/00219991(87)90041-6

Thompson, K. W. (1990). Time-dependent boundary conditions for hyperbolic systems, $\{$ II $\}$. Journal of Computational Physics, 89, 439-461. http://doi.org/10.1016/00219991(90)90152-Q

UNFCCC. (2016). The Paris Agreement - main page.

Wang, J., Ryan, D., Anthony, E. J., Wildgust, N., \& Aiken, T. (2011). Effects of impurities on $\mathrm{CO} 2$ transport, injection and storage. Energy Procedia, 4, 3071-3078. http://doi.org/10.1016/j.egypro.2011.02.21 9

Wang, J., Wang, Z., Ryan, D., \& Lan, C. (2015). A study of the effect of impurities on $\mathrm{CO} 2$ storage capacity in geological formations. International Journal of Greenhouse Gas Control, 42, 132-137. http://doi.org/10.1016/J.IJGGC.2015.08.0 02

Yang, M., Song, Y., Ruan, X., Liu, Y., Zhao, J., \& Li, Q. (2012). Characteristics of CO2 hydrate formation and dissociation in glass beads and silica gel. Energies, 5(4), 925-937. http://doi.org/10.3390/en5040925 
Ziabakhsh-Ganji, Z., \& Kooi, H. (2014).

Sensitivity of Joule-Thomson cooling to impure $\mathrm{CO} 2$ injection in depleted gas

reservoirs. Applied Energy, 113, 434-451.

http://doi.org/10.1016/j.apenergy.2013.07.

059 